\title{
Biodiversity Studies of Insect Fauna Order Coleoptera of Ajmer
}

\author{
Dr Rashmi Sharma
}

\author{
Dept. Of Zoology Spc Gca Ajmer Rajasthan India
}

\begin{abstract}
Ajmer is located in the center of Rajasthan (INDIA) between $25^{0} 38$ " and $26^{0} 58$ " north 75
022 " east longitude covering a geographical area of about $8481 \mathrm{sq} \mathrm{km}$ hemmed in all sides by Aravalli hills. About 7 miles from the city is Pushkar lake created by the touch of lord Brahma. The Dargah of khawaja Moinuddin chisti is holiest shrine next to Mecca in the world. Ajmer is abode of certain flora and fauna that are particularly endemic to semi-arid and are specially adapted to survive in the dry waterless region of the state. Coleoptera. Availability of beetles were more during the night hours and population seemed to be Confined to the light areas.Beetles mean sheathed wings means two pairs of wings are present. Beetles have been Studied for centuries. Following Beetles are recorded in AJMER.
\end{abstract}

Key words: Ajmer, Faunal diversity, Coleoptera, Aravalis.

\section{Introduction}

Ajmer is located in the center of Rajasthan (INDIA) between $25^{0} 38$ " and $26^{0} 58$ " north Latitude and $73^{\circ} 54$ " and $75^{\circ} 22$ " east longitude covering a geographical area of about $8481 \mathrm{sq} \mathrm{km}$ hemmed in all sides by Aravalli hills. About 7 miles from the city is Pushkar lake created by the touch of lord Brahma. The Dargah of khawaja Moinuddin chisti is holiest shrine next toMecca in the world.

Ajmer is abode of certain flora and fauna that are particularly endemic to semi-arid and are specially adapted to survive in the dry waterless region of the state. Coleoptera Beetles means sheathed wings means two pairs of wings are present.

Availability of beetles were more during the night hours and population seemed to be Confined to the light areas.

The order contains more species than any other order, constituting almost $25 \%$ of all known animal life-forms. About $40 \%$ of all described insect species are beetles (about 400,000 species), and new species are discovered frequently. The largest taxonomic family, the Curculionidae the weevils or snout beetles), also belongs to this order.

The diversity of beetles is very wide-ranging. They are found in almost all types of habitats, but are not known to occur in the sea or in the polar region They interact with their ecosystem in several ways. They often feed on plants and fungi, break down animal and plant debris, and eat other invertebrates. Some species are prey of various animals including birds and mammals.

Certain species are agricultural pests, such as the Colorado potato beetle Leptinotarsa decemlineata, the boll weevil Anthonomus grandis, the Red flour beetle Tribolium castaneum, and the mungbean or cowpea beetle Collosobruchus maculates while other species of beetles are important controls of agricultural pests. For example, beetles in the family Coccinellidae ("ladybirds" or "ladybugs") consumeaphids, scale insects, thrips, and other plant-sucking insects that damage crops.

\section{Methodology}

Field observations were made during March to April and September to November in different areas of Ajmer East, West, North and South AJMER with varied habitats like gardens, hilly areas parks mountains, vegetable areas, open fields, agricultural areas and other cultivated areas.

\section{Observations and Results}

During the course of present field investigations 180 families have been reported. The detail of Family, name of species and common name are given below. Tenebrionoidea was found to be most dominant Super family, followed by Super family Cucujoidea , followed by Elateroidea and then Scarabaeoidea followed by Adephaga. 
Some species were found in all months except extreme winters i e December and January February and extreme summer May June. Some species were quick fliers others were shy in nature.

The present study reveals that Carabidae and Dytiscidae Were the first to emerge (March) and Curculionidae was the most late arrival emerging in the month emerging in the month of April. The peak Beetle activity was observed in the month of July to October.

\title{
Order Coleoptera
}

Suborder Adephaga (Schellenberg 1806).

Amphizoidae (Aquatic beetle Trout stream beetle Amphizoa striata.)

Aspidytidae (Cliff water beetles Aspidytes niobe.).

Carabidae (ground beetles).

Dytiscidae (Water diving beetles).

Gyrinidae (Whirling beetles).

Haliplidae(Water beetles crawling).

Hygrobiidae (Aquatic beetles native to Europe, N. Africa, China and Australia).

Meruidae (Aquatic beetles Meru phyllisae).

Noteridae (Burrowing water beetle).

Rhysodidae (Wrinkled bark beetle).

Trachypachidae( False ground beetle leaf litter conifer).

Suborder Archostemata Kolbe, 1908.

Crowsoniellidae (Monotypic sp) Italy calcareous soil base of chestnut tree.

Cupedidae Tenomerga mucida.

Jurodidae (East Russia).

Micromalthidae (Telephone pole beetle).

Ommatidae (Australia and South America).

\section{Suborder Myxophaga}

Hydroscaphidae(Water b Skiff Hydroscapha natans).

LepiceridaeMyxophagan beetles.

Sphaeriusidae (Sphaerius acaroids).

Torridincolidae (Torrent beetle)

\section{SubOrder Polyphaga}

Infra order a. Bostrichiformia

a 1 Super family Bostrichoidea

Anobiidae

Bostrichidae

Dermestidae (Skin beetle).

Jacobsoniidae

Nosodendridae

\author{
a 2 Superfamily Derodontoidea \\ Derodontidae \\ $b$ Infra order Cucujiformia \\ b 1 Super family Chrycomeloidea \\ Cerambycidae (long horn beetle) \\ Chrysomelidae (Leaf beetle) \\ Bruchidae and Cassidae \\ Megalopodidae \\ Orsodacnidae
}

Superfamily cleroidea

Acanthocnemidae

Chaetosomatidae

Cleridae

Melyridae

Phloiophilidae

Phycosecidae 
Prionoceridae

Trogossitidae

\section{Super family cucujoidea}

Alexiidae

Biphyllidae

Boganiidae

Bothrideridae

Byturidae

Cavognathidae

Cerylonidae

Coccinellidae (lady birds)

Corylophidae

Cryptophagidae

Cucujidae

Discolomatidae

Endomychidae

Erotylidae

Helotidae

Hobartiidae

Kateretidae

Laemophloeidae

Lamingtoniidae

Languriidae

Latridiidae

Monotomidae

Nitidulidae

Passandridae

Phalacridae

Phloeostichidae

Propalticidae

Protocucujidae

Silvanidae

Smicripidae

Sphindidae

\section{Super family curculinoidea}

Anthribidae

Attelabidae

Belidae

Brentidae

Caridae

Curculionidae (snout beetle true weevil)

Scolytinae bark beetle

Ithyceridae

Nemonychidae

\section{Super family Lymexyloidea}

Lymexylidae

\section{Super family Tenebrionoidea}

Aderidae

Anthicidae

Archeocrypticidae

Boridae

Chalcodryidae

Ciidae 
Melandryidae

Meloidae gyllenhal blister beetle

Mordellidae

Mycetophagidae

Mycteridae

Oedemeridae

Perimylopidae

Prostomidae

Pterogeniidae

Pyrochroidae

Pythidae

Ripiphoridae

Salpingidae

Scraptiidae

Stenotrachelidae

Synchroidae

Tenebrionoidea (Darkling beetle false ground beetle.)

Tetratomidae

Trachelostenidae

Trictenotomidae

Ulodidae

Zopheridaer

Infra order Elateriformia

Superfamily Buprestoidea

Buprestidae

Schizopodidae

Super family Byrrhoidea

Super family Dascilloidea

\section{Superfamily Elateroidea}

Artematopodidae

Brachypsectridae

Cantharidae (Soldier and Sailor beetles)

Cerophytidae

Drilidae

Elateridae (Click beetles)

Eucnemidae

Lampyridae

Lycidae

Omalisidae

Phengodidae

Plastoceridae

Podabrocephalidae

Rhinorhipiodae

Telegeusidae

Throscidae

\section{Super family Scirtoidea}

Clambidae

Decliniidae

Eucinetidae

Scirtidae

Infra order Scarabaeiformia

Superfamily Scarabaeoidea

Belohinidae

Bolboceratidae

Ceratocanthidae 
Diphyllostomatidae

Geotrupidae

Glaphyridae

Glaresidae

Hybosoridae

Lucanidae (Stag beetle)

Ochodaeidae

Passalidae

Pleocomidae

Scarabaeidae

Dynastidae(rhinoceros beetle)

Trogidae

Infraorder Staphyliniformia

Superfamily Hydrophiloidea

Histeridae

Hydrophilidae

Sphaeritidae

Synteliidae

\section{Superfamily Staphylinoidea}

Agyrtidae

Hydraenidae

Leiodidae

Ptiliidae

Scydmaenidae

Silphidae

Staphylinidae (rove beetle)

Scaphidiinae

Pselaphinae

\section{SubOrder Protocoleoptera}

Super family Tshekardocoleoidea

Tshekardocoleoidae

Labradorocoleoidae

Oborocoleoidae

\section{Superfamily permocupedoidea}

Permocupedidae

Taldycupedidae

\section{Superfamily Permosynoidea}

Ademosyndidae

Permosynidae

Table 1 Beetles of AJMER

\begin{tabular}{|c|c|c|c|c|}
\hline S. No. & Family/Scientific name & $\mathrm{M}$ & Abundance & Habitat \\
\hline 1 & Amphizoidae & $R s$ & $C$ & $A$ \\
\hline 2 & Aspidytidae & $R s$ & $C$ & $A$ \\
\hline 3 & Carabidae & $R s$ & $C$ & $A$ \\
\hline 4 & Dytiscidae & $R s$ & $C$ & $A$ \\
\hline 5 & Gyrinidae & & $C$ & $A$ \\
\hline 6 & Haliplidae & $R s$ & $C$ & $A$ \\
\hline 7. & Hygrobiidae & & $C$ & $A$ \\
\hline 8 & Meruidae & $R s$ & $C$ & $A$ \\
\hline 9 & Noteridae & $R s$ & $C$ & $A$ \\
\hline 10 & Rhysodidae & $R s$ & $C$ & $A$ \\
\hline 11. & Trachypachidae & $R s$ & $C$ & $A$ \\
\hline 12. & Crowsoniellidae & $R s$ & $C$ & $T$ \\
\hline 13 & Cupedidae & $R s$ & $C$ & $T$ \\
\hline 14 & jurodidae & $R s$ & $F$ & $T$ \\
\hline 15 & Micromalthidae & $R s$ & $C$ & $T$ \\
\hline
\end{tabular}




\begin{tabular}{|c|c|c|c|c|}
\hline 16 & Ommatidae & $R s$ & $C$ & $T$ \\
\hline 17 & Hydroscaphidae & $R s$ & $C$ & $T$ \\
\hline 18 & lepiceridae & $R s$ & $C$ & $T$ \\
\hline 19 & Sphaeriusidae & $R s$ & $C$ & $T$ \\
\hline 20 & Torridincolidae & $R s$ & $C$ & $T$ \\
\hline 21 & Anobiidae & & $C$ & $T$ \\
\hline 22. & Bostrichidae & $R s$ & $C$ & $T$ \\
\hline 23. & Dermestidae & $R s$ & $C$ & $T$ \\
\hline 24 & Jacobsoniidae & $R s$ & $C$ & $T$ \\
\hline 25 & Nosodendridae & $R s$ & $C$ & $T$ \\
\hline 26 & Derodontidae & $R s$ & $C$ & $T$ \\
\hline 27 & Cerambycidae & $R s$ & $C$ & $T$ \\
\hline 28 & Chrysomelidae( bruchidae and cassidae) & $R s$ & $C$ & $T$ \\
\hline 29 & Megalopodidae & $R s$ & $C$ & $T$ \\
\hline 30 & Orsodacnidae & $R s$ & $C$ & $T$ \\
\hline 31 & Acanthocnemidae & $R s$ & $C$ & $T$ \\
\hline 32 & Coccinellidae & $R s$ & $C$ & $T$ \\
\hline 33 & Curculionidae & $R s$ & $C$ & $T$ \\
\hline 34 & Meloidae & $R s$ & $O$ & $T$ \\
\hline 35 & Scraptiidae & $R s$ & $C$ & $T$ \\
\hline 36 & Tenebrionidae & $R s$ & $C$ & $T$ \\
\hline 37 & Cantharidae & $R s$ & $C$ & $T$ \\
\hline 38 & Elateridae & $R s$ & $C$ & $T$ \\
\hline 39 & lucanidae & $R s$ & $C$ & $T$ \\
\hline 40 & Scarabaeidae & $R s$ & $C$ & $T$ \\
\hline 41. & Dynastidae & $R s$ & $C$ & $T$ \\
\hline 42. & Hydrophilidaei & $R s$ & $C$ & $T$ \\
\hline 43. & Silphidae & $R s$ & $C$ & $T$ \\
\hline 44. & Staphylinidae & $R s$ & $C$ & $T$ \\
\hline 45. & Tshekardocoleoidae & $R s$ & $C$ & $T$ \\
\hline 46. & Permocupedidae & $R s$ & $C$ & $T$ \\
\hline 47. & Ademosyndidae & $R s$ & $C$ & $T$ \\
\hline 48. & Permosynidae & $R s$ & $C$ & $T$ \\
\hline & & & & \\
\hline & & & & \\
\hline
\end{tabular}

Rs- Resident, Sm- Summer visitor, Wm- Winter Visitor, C-common,

F- Frequent, O-Ocassional, $R$ - Rare, $T$-Terrestrial, A-Aquatic.

\section{Discussion}

During the course of present field investigation, 180 species of beetles were Observed.

The detail list of family, name of species habitat, status, abundance is Provided.

Tenebrionoidea was found to be most dominant Super family, followed by Super family Cucujoidea, followed by Elateroidea and then Scarabaeoidea followed by Adephaga.

The present study reveals that Carabidae and Dytiscidae Were the first to emerge (March) and Curculionidae was the most late arrival emerging in the month emerging in the month of April. The peak Beetle activity was observed in the month of July to October.

There was no beetle activity during peak summer (May, June) and peak winter (December January February). The overall beetle activity was observed April during Night and September, October, November night .Depending upon weather, month, season, host plant temperature and type of species concerned.

\section{Conclusion}

The present field investigation revealed that district Ajmer is rich in floral and faunal Wealth. Specially in coleopteran beetle diversity. However its biological diversity not been documented till date. We can conclude that coleopteran fauna of the area is increasing. The area needs to be continuosly monitored and efforts be made to document its unknown floral and faunal wealth and there is need to have a vision document on the sustainable development of the district care and focus on documentation and conservation of its rich biodiversity.

The Aravallis are being continuously cut for house construction and urbanization. There should be a check on the activity.

During the course of present field investigation, 180 families. The detail list of family, name of species habitat, status, abundance is provided. 
The present study reveals that Carabidae and Dytiscidae Were the first to emerge (March) and Curculionidae was the most late arrival emerging in the month emerging in the month of April. The peak Beetle activity was observed in the month of July to October.

There was no beetle activity during peak summer (May, June) and peak winter (December January February). The overall beetle activity was observed April during night and September, October, November night .Depending upon weather, month, season, host plant temperature and type of species concerned.

\section{Acknowledgement}

We are thankful 1 to Principal SPC GCA and Dr J. R. B. Alfred Director Zoological Survey Of India and Dr S. Z. Siddiqui Officer incharge zoological survey of India freshwater biological station Hyderabad, for facilities editing and encouragement.

\section{References}

[1]. Lawrence,J.F., Newton, A.F. Jr (1995) Families and subfamilies of Coleoptera (with selected genera, notes, references, and data on family group names), pp 779-1006. In:Pakaluk, J., Slipinski,

[2]. S.A.(eds), Biology, phylogeny, and classification of Coleoptera:Papers celebrating the $80^{\text {th }}$ birthday of Roy A.Crowson. Muzeum I Instytut zoologii PAN, Warszawa.

[3]. Ross H. Arnett, Jr. and Michael C. Thomas, American Beetles (CRC Press , 2001-2002).

[4]. Retrieved from "https://en.wikipedia.org/w/index.php?title=List_of_the_order_Coleoptera\& Oldid=686462961". 